Check for updates

The BMJ

Cite this as: $B M / 2021 ; 373: n 1157$ http://dx.doi.org/10.1136/bmi.n1157 Published: 05 May 2021

\title{
Covid-19: Female NHS and care staff report deteriorating health because of pandemic
}

\section{Gareth lacobucci}

Female health and care staff in England have experienced significantly worsening physical and mental health since last year as a result of working through the covid-19 pandemic, a survey ${ }^{1}$ has found.

Four out of five ( $80 \%)$ female respondents to a poll by the NHS Confederation's Health and Care Women Leaders Network reported that their job had a greater negative impact than usual on their emotional wellbeing as a result of the pandemic, compared with $72 \%$ from a similar poll last June.

The latest survey, conducted in February and March 2021 , also found that $65 \%$ of women reported a negative impact on their physical health, a rise from $52 \%$ last June.

More than 1200 NHS staff-including doctors, nurses, managers, and others-responded to at least part of the survey. Some 900 staff completed it in full, including 809 who identified as female. The results cover the responses of the female respondents who answered every question.

The survey highlighted some positive experiences for female staff during the pandemic, including more opportunities for flexible working, improved teamwork, and better access to technology. It also revealed hopes that flexible working and better work-life balance could continue.

But it also found that caring responsibilities outside of work have grown since last summer for female staff, with respondents reporting taking on more hours of unpaid caring responsibilities. This was particularly the case for respondents with children because of school closures and reduced hours, which the network said posed "serious implications for career progression opportunities.”

Female staff with long term health conditions reported a greater negative impact from the pandemic on their physical health compared with those without long term conditions, and also reported feeling less safe sharing concerns with managers.

And some $87 \%$ of respondents with long term conditions reported that their job has had a more negative impact on their emotional wellbeing since the pandemic started, compared with $79 \%$ of those without. The network said it would work with employers and national partners to understand the reasons for this disparity and how to support the workforce in light of the findings.

Samantha Allen, chair of the NHS Confederation's Health and Care Women Leaders Network and chief executive of Sussex Partnership NHS Foundation Trust, said, "We need to see tailored support for female staff and this should include recruitment, retention, flexible working, and career progression.
We want to create conditions where our workforce is valued and all can progress in their careers, particularly those who work less than full time.

"We need to make sure we look after people, after the difficult experiences they have been through during the pandemic while supporting patients, families, and carers and with the increased responsibilities of caring for children and adults outside of work. Looking after our staff will enable us to continue looking after the people who need our services. The findings of this survey must be a driver of real and lasting change.”

Henrietta Hughes, national guardian for the NHS, said, "The pandemic has impacted on us all, emotionally and physically, and has exacerbated inequalities which can no longer be tolerated. This report shows how vital it is, not just for people to feel able to speak up about anything which gets in the way of them doing their job, but for managers to be supported to listen up and for leaders to follow up so that the right actions are taken."

NHS Confederation. Covid-19 and the female health and care workforce survey update. May 2021. www.nhsconfed.org/resources/2021/05/covid19 and-the-female-health-and-care-workforce-survey-update.

This article is made freely available for use in accordance with BMJ's website terms and conditions for the duration of the covid-19 pandemic or until otherwise determined by BMJ. You may use, download and print the article for any lawful, non-commercial purpose (including text and data mining) provided that all copyright notices and trade marks are retained. 